Indexaciones: Repositorio de Revistas UCR, DIALNET, Latindex, REDALYC Directorio y recolector de recursos digitales del Ministerio de Cultura de España, Directory of Open Access Journals. Diálogos Revista Electrónica de Historia ISSN 1409-469X. Número especial 2008. Dirección web: http://historia.fcs.ucr.ac.cr/dialogos.htm

\section{“GARCÍA PÉREZ Y EL PERMANENTE SUFRIMIENTO DE UN PUEBLO”}

Mg. José Darío Cedeño León

Universidad Nacional del Santa -Calle San José No 739, Laredo - Trujillo, Perú

- Tlf. 044-435188 y Cel. 044-9704940

- jcedenoleon@gmail.com 


\section{RESUMEN}

Llegar al escenario electoral de junio del 2006, y ver -con mucha impotencia- cómo sucedía lo inaudito, es decir, Alan García Pérez era elegido por segunda vez como presidente constitucional del Perú, a pesar de que ha quedado registrado en la Historia Nacional como el mandatario que batió el record inflacionario, además de saber que la corrupción y el festinación del Fisco por parte de sus correligionarios, son otras de las características del aprismo gobernante de los '80, amén de los innumerables casos de genocidio demostrado y que aún esperan en la CIDH, casos pendientes, nos llevó a indagar en nuestra historia casos semejantes. Aun cuando conocemos que para esta nueva elección García Pérez contó con el apoyo de toda la derecha, así como de EE.UU., es desalentador saber que el pueblo accedió a los coqueteos de la derecha y el APRA, así como sucumbió ante los demagógicos ofrecimientos de este hábil orador, aun cuando su retórico estaba notoriamente desgastada. En efecto, esto nos impulsó a buscar en nuestra historia, similares casos que ya generan un lugar común.

Para ello se ha tenido que hacer una búsqueda de información bibliográfica para reconocer casos como el de Castilla, Piérola, Leguía, Belaúnde, hasta llegar al caso del actual mandatario peruano.

Concluimos que hay una tendencia al olvido, producto de cierta indiferencia histórica, muy a despecho de lo que en plena coyuntura electoral se vive. Tendencia esta que, para unos suena a masoquismo, para otros es el producto de un eficiente trabajo de los grupos de poder, para ganarse a un pueb que, a pesar del hartazgo frente a ellos, opta por tales, azuzados por el temor de una alternativa de real cambio. 


\section{DESARROLLO TEMÁTICO}

Durante la época a la que Basadre llama “Era de la prosperidad falaz” (H. Bonilla la denomina “Era del guano”), período comprendido entre los años 1840-1879, debido a que Europa vivía la denominada "Segunda revolución agraria”, la demanda del rico recurso peruano fue inimaginablemente grande; así las cosas, los ingresos para la Caja Fiscal obviamente también fueron impensados. Empero, “las ingentes cantidades, no sólo no generaron desarrollo si no que, sobretodo, fue el argumento utilizado por los políticos de entonces para endeudar a nuestro país a extremos muy alarmantes” (1). En efecto, la deuda que el Estado Peruano contraía iba aumentando en forma desmedida, pues hasta en momentos de mayores ingresos, el Perú “estiraba la mano” en búsqueda de préstamos.

A continuación se enfocan momentos en que el Estado Peruano vive situaciones que comprometen a mandatarios con una dilapidación de recursos del fisco.

\section{CASTILLA, SU ASCENSO AL PODER Y EL COMPROMISO CON LA PLUTOCRACIA GUANERA}

Es necesario puntualizar algunos aspectos previos al gobierno de Ramón

(1) Cedeño, 2005 
Castilla. Para esto es necesario ser claro en algo: el 09 de diciembre de 1824 bien puede ser tomado como “el momento en que se jodió el Perú”, en la medida que, como sabemos, toda la lacra que representaba la oficialidad realista, se quedó aquí, incorporándose al ii ejército peruano!!. Naturalmente....como sabemos, lo que sigue históricamente es una etapa tipificada por J. Basadre como El primer militarismo, etapa ésta en la que reina la anarquía militar, un caos propiciado por los caudillos militares que "gozaban del prestigio que significaba el vestir el uniforme del ejército que había derrotado a los realistas", y que les generaba un sentimiento de "capacidad” para asumir el control del aparato estatal. Es decir, los capitulados gobernaron el país desde ese momento, y lo hicieron con la mayor de las voracidades, ambiciones personales y desprecio por la masa indígena, aquella que nunca fue redimida.

Tres lustros después, vimos uno de los pocos intentos en que nuestra historia atestigua circunstancias presidenciales por hacer bien las cosas, nos referimos a la Confederación Perú-boliviana. Sí, el recuperar la capacidad comercial de puertos peruanos, castigados por el olvido desde 1778 (Reglamento de Libre Comercio) y ampliamente superados por Valparaíso; así como intentar poner fin -aun cuando muy severamente- al caos militar, o disponer una descentralización que no sólo daba a las provincias un protagonismo que hubiese permitido el desarrollo económico del Estado Confederado, sino que rompía con siglos de centralismo dañino que sólo había beneficiado a élites limeñas (los ricos del Perú), eran medidas serias a las que se debía apoyar. Pero los enemigos de Perú y de Bolivia, obviamente se opusieron radicalmente. Pero, ¿quiénes eran estos enemigos?; la respuesta, silenciada por los historiadores tradicionalistas, tiene que ser contundente: Chile por el peligro que representaba dejar de percibir los únicos importantes ingresos que tenía vía Valparaíso, en ausencia de recursos naturales que explotar. Los ricos del Perú -quienes nunca han sentido, ni sentirán al país como algo suyo; véase el caso de los Wong de hoy- que vieron peligrar sus privilegios con la "amenaza” descentralista. Pero, de este grupo hay que resaltar las decididas pataletas de don Felipe Pardo y Aliaga, genuino representantes de esas antinacionales clases dominantes (fue un Pardo, obviamente). Y, 
finalmente, los militares -si, los capitulados o sus familiares- que veían un peligro severo para sus aspiraciones caudillescas.

Bueno pues, estos tres enemigos del Perú se unieron y se lanzaron contra la Confederación con la argucia de que iban “a restaurar la independencia del Perú, la que había perdido por la presencia de un boliviano, Santa Cruz”. El entonces general había nacido en territorio que hacia ese año era la joven Bolivia, creada por los soterrados manotazos de Bolívar; pero pretendían olvidar que cuando él nació, La Paz era territorio peruano. Intentaron ignorar su condición de presidente del Perú hacia 1827, del mismo modo en que se callaron cuando La Mar jefaturó el país en dos ocasiones, porque cuando éste nació, Cuenca, su terruño, era parte de Perú. Entonces, lo de “restauración” sólo era una argucia para negarle a la Confederación el derecho de hacer bien las cosas.

Pero, aquí el problema era la participación de Castilla, Gamarra, Gutiérrez de La Fuente, Vidal, Vivanco, Elías, entre otros caudillos, como aliados de Chile contra Perú. Más podían sus ambiciones personales que el derecho peruano al desarrollo.

Bien, ese mismo Castilla, el "restaurador”, fue escogido por la plutocracia guanera “para que ponga orden en el país”. Un orden no sólo político y social sino, orden en la economía, pues se acababa de recibir la certeza de que el guano peruano era un potencial recurso generador de inmensa riqueza. Y en efecto, logró consenso entre los mandos militares, ofreciéndoles participación en el control del erario nacional, y en economía ejecutó el Primer Presupuesto Nacional.

Veamos algunas de sus acciones de gobierno.

El interés por una satisfactoria venta del guano en el mercado europeo se inició, justamente, en su gobierno, pues de las 28 Libras Esterlinas (LE) por Tn hacia 1841 fue bajando hasta 10 LE en 1842, llegando, incluso a las 8 LE hasta 1846. Cuando se logró demostrar su calidad inigualable, en abril del '47 llegó a cotizarse en 10 LE, pero para esto, Castilla ya había negociado con importantes grupos económicos y familias (plutocracia) 
con vínculos europeos su participación. Allí están los Quiroz, Aquiles Allier, los Candamo, Canevaro, Castañeda, Ortiz de Villate, Goyeneche y Gamio, Unanue, Sancho Dávila, Barreda y Osma, Ugarte, Montané, las compañías Gibbs, Puymirol Poumarox, etc. A mediados de 1847 se inicia la etapa de las consignaciones, a precios que de a poco iban elevándose hasta llegar a las 28LE por Tn -téngase en cuenta que 1 LE se cotizaba a 5 pesos-.

Basadre publica cálculos oficiales del guano exportado. (2)

- Hasta 1849: 154533 Tns.

- Hasta 1850: 140700 Tns.

- Hasta 1851: 199045 Tns.

Sin embargo, estas cifras que debieron representar algo más de tres millones de pesos, sólo son las oficiales pues debe quedar muy claro que para nadie (como se demostrará líneas adelante) era un secreto que al Estado, los consignatarios le robaban en el peso y en el precio (3). De aquí pues, se desprende el ilícito enriquecimiento de los consignatarios, el mismo ¿secreto? a voces que durante la época de Castilla sólo se “embalsaba” como potencial denuncia pública que estalló (los castillistas lo hicieron) durante la gestión de Echenique, nada menos que el delfín de Castilla, su brazo derecho, el escogido por el mismo mariscal para sucederle en el mando, a falta de normas que permitan la reelección presidencial. Pero dicha denuncia estaba orientada a preparar el camino para el retorno de Castilla.

Pero aquí interesa el tema del manejo de la cosa pública. En esto hay que ser contundentes al asirnos y publicar documentos que revelan el verdadero actuar de Castilla. ¿Qué hizo con los recursos financieros provenientes de la venta de guano?. Esto tiene que ver con aquel calificativo que Basadre le asigna a aquella época: Época de la prosperidad falaz. (4) La Falaz prosperidad del guano (1842-1866).

Y es que, como Heraclio Bonilla afirma (5), "hasta en los momentos de

(2) BASADRE, 1983

(3) Al Estado peruano le correspondía el 65\% y al consignatario el 35\% delas ventas.

(4) BASADRE, 1983 
mayor bonanza económica, producto de las ventas del guano, el Perú estiraba la mano para pedir préstamos”. Pero, ¿cómo no pedir? Si había que pagar favores políticos a la plutocracia, si había que recompensarla, inclusive tal y conforme lo estipulaba la Capitulación de Ayacucho. Veamos, Basadre apunta que “La bonanza fiscal dio lugar a las leyes promulgadas el 17 de setiembre y 29 de diciembre de 1847, el 10 de marzo de 1848 y el 16 de marzo de 1850, que ordenaron el pago a los perjudicados en las guerras por la independencia y en contiendas posteriores."(6); al respecto, Virgilio Roel titula este panorama como "La escandalosa consolidación de las deudas interna y externa"; y es que, en efecto, Castilla -pagando el favor político de la plutocracia- reconoció como acreedores a todo aquel - “notable ciudadano”- que se consideraba en derecho de reclamarle al Estado el pago de una deuda concebida por éste, en el pasado, durante las guerras por la independencia; es decir, cuando el Estado era virreinal, inclusive. Había que reconocer deudas concebidas por el virrey cuando éste recurría a préstamos para la adquisición de armas o para el aprovisionamiento de las tropas virreinales, con todo tipo de suministros. La siguiente transcripción de tan prestigioso historiador, acaso el más documentado de esta etapa de la historia peruana, es de por sí, muy ilustrativa: En “La primera Ley, de setiembre de 1847(reconoce todo préstamo en dinero o en especie desde 1823 y) los interesados debian calificar sus créditos ante las autoridades designadas en las resoluciones vigentes, sin que sirvieran de obstáculo los descuidos de los empleados en la administración pública si no existían documentos donde constaba el crédito” (ii !!) 7.

"Por la segunda Ley, de diciembre del mismo año, se amplió dicho reconocimiento a todos los créditos registrados o que se registraran, contraídos desde el 19 de setiembre de 1820 (...)” sin que sirvieran de obstáculo las omisiones que presentaran los documentos del reclamante.

Y, en la ley de marzo de 1848 “quedaron fijadas las bases para la liquidación de la deuda interna, mencionando los créditos de que hablaban las leyes de setiembre y diciembre de 1847. así como toda deuda procedente de suministros,

(5) BONILLA, 1980.

(6) Basadre,Id.

(7) subrayado del autor 
cupos, contribuciones de guerra, empréstitos voluntarios o forzosos. El inciso $2^{\circ}$ del artículo $4^{\circ}$ de esta ley dispuso que cuando resultase dudoso el cargo reclamado contra el Fisco, se resolviese la cuestión de acuerdo con los principios de equidad a favor del acreedor del Estado. El inciso $3^{\circ}$ del mismo artículo ordenó que en las deudas contra la hacienda pública no hubiera lugar a excepción de prescripción.”. Aquí es preciso anotar que, como lo señala Roel (8), antes de dictarse las normas de la escandalosa “consolidación”, la deuda interna peruana era de casi un millón de pesos, pero, al concluir el mandato de Castilla dicha deuda se septuplicó, pero, como lo reconoció en su mensaje al Congreso Extraordinario de 1851, se había pagado 4’320,400 pesos, añadiendo que "La ley de consolidación es un principio fecundador que ha brindado al país innumerables beneficios; es una ley de consuelo y de sólidas esperanzas para una multitud de familias, una tabla de salvación en el naufragio de tantas fortunas, un nuevo elemento de bienestar y orden”... huelgan los comentarios respecto a lo que José Arnaldo Márquez tipificó como la orgía financiera del Perú.

Que hubo una orgiástica actitud en el manejo de los recursos del Fisco lo demuestra, además, el compromiso asumido por los capitulados, los enemigos de la Confederación, en este caso Castilla quien, fiel a los que dejaron establecido los Sucres y Bolívares en el oprobioso documento de diciembre de 1824, obligaron al país a "pagar a Colombia los gastos que hizo esta república para auxiliarlo en la guerra de su independencia" (Basadre, id.), de igual modo se procedió con Chile mediante la convención de 12 de setiembre de 1848, posteriormente con Venezuela, mediante convenio firmado el 25 de julio de 1853, en el que se le reconoce una deuda de hasta 3 millones de pesos. Inclusive, EE.UU. también reclamó deudas, las que se le pagó en 1853. Pero la orgía financiera continuó durante el prolongado mandato de Castilla, es decir, durante la gestión de su delfín, Rufino Echenique. Vale recordar que don Nicolás de Piérola y Flores (sí, padre del inefable Piérola, quien nos vendió e hizo propicio el triunfo

de Chile en la infausta guerra del Pacífico), en 1853 señaló, oficialmente, que la Caja de Consolidación había reconocido hasta julio de ese año la suma de 23’211,400 pesos. Sólo en deuda.

(8) Roel, 1993 
Pero los egresos no sólo fueron deuda, además están los gastos hechos en la manumisión de los esclavos negros -léase compra de la libertad, favoreciendo a los esclavistas, para variar, la plutocracia-, acto que ha sido permanentemente motivos de loas por parte de la historia tradicional cuando se dice que Castilla liberó a los negros de la esclavitud, se le llama antiesclavista y se oculta el hecho que durante su gestión, y para suplir la mano de los negros, se trajo a esclavos chinos, los coolies.

Líneas atrás se mencionaba que Echenique fue el delfín de Castilla, eso es documentariamente cierto. La orgía económica y financiera de la que nos habla José Arnaldo Márquez, es responsabilidad de ambos. Recordemos, Echenique estuvo muy vinculado con los líderes "restauradores", con Vivanco, de quien fue partidario, con Castilla, y hay que tener en cuenta sus vínculos familiares y su entorno social con los Benavente, Tristán, entre otros.

Cuando afirmamos lo de "delfín" no es gratuito pues había ocupado los más altos cargos en el gobierno del mariscal, llegando incluso, a ser Presidente del Consejo de Estado -hoy, vicepresidente-. Para su campaña electoral, apunta Basadre, hizo uso de un arma indispensable: el dinero. "Por primera vez acaso, después de Orbegoso (...) un personaje acaudalado apareció pretendiendo la presidencia de la República. Valdivia dice: 'El general Echenique repartió en la república mucha plata y logró obtener la mayoría de votos'(...)". 80,000 pesos gastó Echenique (el doble de lo que había gastado Vivanco) para ser elegido presidente además del apoyo del gobierno (de Castilla) que favoreció a todo trance su elevación.

No obstante todo ello, las pugnas y acusaciones mutuas entre Castilla y su delfín, fueron hechos protagónicos en esa etapa de la historia peruana. Mientras el país se endeudaba a niveles alarmantes, en una época de boom guanero, de auge en la producción de un bien muy preciado, los mutuos reproches tenían como testigos a una muy favorecida plutocracia que nuevamente apostó por Castilla, haciendo uso, inclusive, de dinero mal 
venido perteneciente al pueblo peruano. $\mathrm{Al}$

respecto, es oportuno reproducir la cita que Basadre hace del diputado Evaristo Gómez Sánchez en el Congreso de 1860 “QQué fue, señores, la elección del 55? ¿Quién no vio los tabladillos electorales convertidos en mercados? ¿Quién no sabe que al tabladillo de la capital de la República mandaban los candidatos a sus agentes o corredores, quienes, colocados lado a lado de las mesas, compraban el sufragio de los libertos y de los hombres pérfidos y más abyectos que llegaban a las urnas, estipulaban el precio de su voto y después de haberlo recibido y sufragado iban a otra parroquia a practicar lo mismo?” .Aquella vez, como hoy, el pueblo votaba por un personaje que, a pesar del dispendio de los recursos fiscales, y con la ayuda de sus demagógicas y populistas obras, compraba el voto, muy a despecho de lo que hubiésemos deseado los peruanos de un presidente.

\section{NICOLÁS DE PIÉROLA Y SUS TRAICIONES AL PERÚ}

Al llegar a enero de 1869, durante el gobierno de José Balta, el dilapidador Echenique era presidente del Senado y fue quien sugirió a Balta que nombre como su ministro de Hacienda a este Piérola, hijo de su antiguo ministro y a quien logró que el Senado le aprobara un proyecto que, en la hora undécima fue convertido en Ley y cuyo texto decía: “Autorizase al Poder Ejecutivo para que procure los fondos necesarios, a fin de salvar el déficit que resulta en el Presupuesto General de la República, que debe regir en el presente bienio, dando cuenta al Congreso” (9) Ley de 25 de enero de 1869). Don Nicolás de Piérola y Villena, actúa como agente de don Augusto Dreyfus, representante de la Casa que fungió de salvadora financista del país. Esto, al parecer, es algo que ya estaba “cocinado” desde antes, pues, designado Ministro, Piérola nombró una comisión integrada por Toribio Sanz y Juan Martín Echenique -hijo del ex presidente, sí, del mismo que lo propuso como Ministro- que viajó a Europa con el pretexto de conseguir una nueva expedición de guano. Dicha Misión encontró (¿) una propuesta: la de la casa Dreyfus y Hermanos para asumir la parte financiera, la deuda del Perú. ¿Pero quién era Dreyfus, realmente?, a fines de los' 50 era una

(9) Ley de 25 de enero de 1869 
asociación conformada por Jerónimo, Isidoro y Próspero Dreyfus, empresa no muy próspera, con exiguos capitales que se dedicaba a la importación de telas de Francia al Perú; desde 1869 aparece de don Augusto como figura dominante, después de haber sido apenas un pariente protegido, casi un empleado de privilegio. Fue la Sociedad General de París la que le apoyó con 60 millones de francos para que este oscuro comerciante importador de joyas y géneros, asuma el negocio de la importación de guano, primero por dos millones de tns. Para, luego, convertirse en una entidad que manejó el destino económico-financiero - e histórico, podría decirse- del Perú. Según anota Roel, "Piérola puso en manos de Dreyfus los destinos del Perú” (Roel, 1991), sí, pues los préstamos que la tristemente célebre transnacional francesa, no sólo eran en exceso onerosos, sino que nos condenaban a una absurda dependencia de dicha empresa, que, a partir de la aprobación del Proyecto de Ley de Monopolio de la explotación, exportación, venta y administración del recurso guanero, actuaba, además, como representante financiero (plenipotenciario) de los intereses peruanos en Europa. El proyecto mereció el repudio del entonces Congreso Peruano -es imperioso recordar la ardorosa lucha por la no aprobación del aludido proyecto, hecha por el parlamentario Bogardus quien denunció ese atentado contra los intereses nacionales-, no obstante, el oficialismo de entonces aprobó tal afrenta contra el país.

Aquí es menester precisar que los consignatarios presentaron un recurso a la Corte Suprema, pidiendo la rescisión del contrato (10) el recurso fue acogido por el fiscal Paz Soldán. El Congreso se dividió en dos, una parte que apoyaba a los consignatarios y otra parte, manipulada por Piérola, había sido comprometida por éste, de manera que el contrato fuera cada vez, más difícil de rescindirlo. Roel (11) indica que, “cuando en agosto de 1870 se inició el debate en el Congreso en torno al Contrato Dreyfus, el gobierno ya le debía a la compañía 20 millones de soles", añadiendo que "El debate fue intenso, pero finalmente el negociado fue aprobado por el Congreso, en octubre de 1870. Fue el triunfo de una parte de los usufructuarios del guano sobre la otra parte, también guanera. Unos y otros gastaron qruesas sumas en propaganda y sobornos."

(10) Roel, cita a 11 consignatarios firmantes

(11) Roel,Ob. Cit. 
Tres años después, el civilismo, en un raptus de nacionalismo desconoció tal compromiso en un acto que merece el reconocimiento del país, pero la reacción de la trasnacional fue denunciar a Perú como país paria, condenándonos al descrédito, en común concierto europeo. Recordemos que sólo seis años después Chile, con objetivos geopolíticos preconcebidos nos declara la guerra y en ello tuvo el apoyo incondicional de Europa en pleno. La negativa europea a vendernos armas y el armamento alemán, italiano, inglés requisados a los chilenos en Tarapacá y lo que se vió objetivamente, después, es una muestra de lo afirmado. ¿Quién trajo a Dreyfus?: Piérola. Pero su negativa acción no queda en estos repudiables incidentes. Va más allá.

Recordemos que Mariano Ignacio Prado fue el presidente peruano que recibió la declaratoria de guerra de Chile, él mismo es quien tras varios meses de colecta nacional con el argumento de “comprar armas en Europa”, se embarcó rumbo al viejo continente el 18 de diciembre de 1879, y NUNCA REGRESÓ. Cuatro días después de su partida sucedió algo insólito: Piérola, ese personaje que facilitó las condiciones para un triunfo chileno, asume el poder en condición de DICTADOR del Perú y desarrolla una desastrosa y antinacional gestión. Recuérdese la construcción de la -denominada por él- Defensa de Lima ii en el cerro San Cristóbal !!, es decir, al norte de Palacio de Gobierno, sin tomar en cuenta que la invasión venía desde el sur. “Ciudad Piérola” la llamaron sarcásticamente en esa época, debido no solamente a su pésima ubicación, pues estaba al norte y el ingreso de los invasores chilenos venía desde el sur, sino además por lo fastuoso de su fiesta de inauguración, amén de que nunca se disparó desde allí una sola bala. Pero también es muy necesario recordar su negativa al apoyo que en un decisivo momento le solicitara Cáceres para, con sus montoneras, atacar a los chilenos -éstos, tras el triunfo en Miraflores y Chorrillos, y seguros de su ingreso a Lima, se encontraban embriagados tras una borrachera triunfal- y sólo ofrecerle un ascenso a fin de acallar cualquier reclamo del Brujo de los Andes.

Como corolario de todo lo hecho contra nuestro país, en el verano de 1881 fugó de Perú ¡¡con pasaporte chileno!! en una desvergonzada actitud símbolo de traición a la Patria. Sin mayores comentarios.

Sí, ese es el mismo Piérola que, 14 años después regresa al Perú y ante el desastroso 
gobierno de Cáceres, y apoyado por un grupo de limeños, ingresa bajo el grito de ¡iVIVA PIÉROLA!! ii muera el tirano !!e inicia un gobierno entreguista en el marco de una influencia civilista. La conducta ¿amnésica? de un sector de la población peruana -aquella que legalmente participaba en la elección presidencial, es decir, la población electoral- ya se ponía de manifiesto.

\section{LEGUÍA, “EL GRANDE DEAMÉRICA”}

No podemos soslayar la presencia, en este escenario que tiene mucho de común -un lugar común en la Historia del Perú- a don Augusto Bernardino Leguía. El mismo personaje que, aliado a los civilistas, inició, hacia 1908, un gobierno descaradamente entreguista, pues entregó territorios a Colombia, Bolivia y Brasil.

Con Colombia, la situación fue aproximadamente así: El gobierno peruano había detectado infiltración de tropas colombianas hacia julio de 1909; nuestros límites estaban definidos por el río Caquetá. El ejecutivo ordena a la guarnición lambayecana al mando de Oscar R. Benavides, repeler la invasión. Así se hizo, la contundencia de las tropas peruanas, hizo retroceder a los colombianos que habían llegado hasta el Putumayo, logrando que el invasor se refugie más allá de los límites trazados en el Caquetá. Justamente cuando las tropas peruanas se disponían a contraatacar, ya sobre territorio de los insolentes invasores, llega un emisario enviado por Leguía con la orden de dejar a las tropas colombianas ocupando ese vasto territorio amazónico(ii!!). Se estaba entregando más o menos unos 225,000 km2, de selvas cargadas de caucho y madera, de la manera más cobarde y entreguista. Téngase en cuenta que la entrega oficial de esa inmensa extensión sólo fue hecha en un nuevo gobierno del entreguista presidente, es decir en 1922; pero, la cobardía, identificada en él hizo que oculte este hecho, RECIÉN EL PUEBLO TOMÓ CONOCIMIENTO DE ESTA ACTITUD ENTREGUISTA TRES AÑOS DESPUÉS, y en forma accidental, cuando un medio escrito argentino lo publicó en Buenos Aires.

Pero, en esos mismos días, campesinos de la parte más oriental de nuestro país 
denuncian penetración de caucheros brasileros, protegidos por tropas del vecino país. Al ser enterado el Ejecutivo de esta situación, la orden fue insólita: dejar avanzar a las tropas brasileras porque hay dos razones de peso: $1^{\circ}$ somos un país amante de la paz; y, $2^{\circ}$ Brasil es un país fuerte, más que Perú, por tanto hay que descartar todo deseo patriota de recuperar algo que "no vamos a poder explotar". Brasil estaba enajenando unos 250,000 km2. de selvas cargadas de caucho y madera, entre otros recursos.

Pero, los vecinos aprovecharon la presencia de este entreguista. Por esos mismos días Bolivia también hizo lo propio y, a pesar de que -al igual que Ecuador- nunca pudieron con armas someter al Perú, igual Leguía les entregó unos 70,000km2.

Ese es el mismo Leguía que, tras una partida repentina por el pésimo gobierno que incluso, tuvo que soportar el asedio que significó el tener sobre sus hombros un pasivo que incluía dolo en el manejo de la cosa pública. Ese mismo Leguía pues, es el mismo que con su discurso basado en la promesa de una "Patria Nueva" frente al atraso que significó el civilismo en el poder -los mismos que lo encumbraron como presidente años atrás-, aparece en 1919 presentándose como el salvador.... y, para variar, el pueblo lo convierte en mandatario para un período que se prolongó por once años. Leguía, como es conocido, hizo de ese Oncenio, un periodo de entreguismo, saqueo; persecución, hostigamiento y encarcelamiento de la oposición. Él concluyó la entrega de territorios a Chile, así como a Colombia.

\section{EL INEFABLE BELAÚNDE TERRY}

Del anterior episodio nos trasladamos a un escenario más cercano: 1968. Golpe de Estado a don Fernando Belaúnde Terry que tuvo como motivaciones la burla a los campesinos con una falsa Reforma Agraria, una creciente devaluación del Sol Peruano, pero, sobre todo una burla más al pueblo peruano en el caso de su recurso petrolero. En 
su discurso como candidato, Belaúnde ofrecía dar solución a una álgida exigencia de la población: nacionalizar la Brea y Pariñas, importantes yacimientos petrolíferos del país. No obstante dicho ofrecimiento - que se postergaba año tras año-y firmada la "nacionalización" de los aludidos yacimientos que incluso habían dado lugar a la formación de condenables enclaves, la IPC logró retener el monopolio de la refinación del crudo en Talara, a la par que se le cediera ciertas áreas para la exploración y explotación en la selva peruana. Las críticas llevan al “escándalo de la página 11”. Esto debido a que Belaúnde es impelido a mostrar limpieza en el convenio de nacionalización y para demostrarlo tenía que exhibir el texto completo del mismo, grande fue la sorpresa ( $\dot{\dot{c}}$ ?) cuando la nación vio que faltaba la página (11) que contenía los verdaderos acuerdos financieros que demostrarían un entreguismo a la transnacional estadounidense.

Recuérdese que la tan prometida Reforma Agraria que nunca llegó, fue la causadetonante para que estalle un foco guerrillero que intentó arrastra, tras de sí, a un importante contingente campesino. Movimiento éste que autodenominado Movimiento de Izquierda Revolucionaria (MIR), y que fuera tratado con desdén por el arquitecto -le consideró”un simple movimiento de abigeos, demostrando una cruel miopía política-, constituyo, a la postre, un importante germen de lo que más tarde, y en su segundo gobierno, sería el nacimiento del más grande grupo subversivo del país: el PC del P, “Sendero Luminoso”.

Tras doce años de gobierno militar, se procesan elecciones y Belaúnde, sí, el mismo que fue repudiado por los escandalosos (y delictuosos) sucesos reseñados, recibe la aprobación mayoritaria del electorado peruano que lo convierte en presidente por segunda vez. Sirvió para su nueva elección, tal vez, la estrategia de no presentarse su partido (AP) a las elecciones para la Asamblea Constituyente, como un amago de rechazo a los militares convocantes, aquellos militares que, 10años antes lo "habían sacado del gobierno”. 


\section{ALAN GARCÍA PÉREZ}

Llegamos a los tres últimos lustros del siglo XX, 1985. Se inicia uno de los gobiernos más desastrosos de nuestra historia. Alan García, con sólo 36 años, mucho carisma y un añoso partido que exhibe como paradigma a un extinto y popularísimo líder, pero también es conocido - en la época- por pregonar una suerte de fundamentalismo: el SEASAP (sólo el APRA salvará al Perú), significa además una comparsa fascistoide, los históricos y temidos búfalos.

A continuación, un breve balance de dicho gobierno.

\section{$1^{\circ}$. EN LO ECONÓMICO.}

Una de las primeras medidas de Alan García cuando recién entró como presidente en julio de 1985, fue congelar los ahorros en dólares a los pequeños ahorristas (los que tenían en ahorros menos de 5,000 dólares), solo se les permitió sacarlos en soles al tipo de cambio oficial que era considerablemente menor a su valor real; de esta forma la clase media se vio afectada directamente y perdió la confianza en el ahorro que es la base fundamental para el bienestar familiar. Desde allí se inicia la pronta extinción de la clase media. Hoy -diciembre del 2006, en su nueva gestión, se ha anunciado una medida similar, orientada a gravar los intereses de ahorros superiores a los siete mil soles, unos $\$ 1$ 800.00. Por otro lado, creó un impuesto de $1 \%$ a los cheques bancarios, es decir que por cada cheque girado el Banco descontaba 1\% del monto (para el gobierno), esta medida causó que la mayoría de personas (y empresas) cerraran sus cuentas corrientes, eran comunes las transacciones en efectivo; es decir el país retrocedió a la era pre-industrial.

Pero hay más para recordar, pues durante los dos primeros años de su gobierno se negó a pagar la deuda externa y con esos fondos subsidió alimentos y realizó aumentos indiscriminados a los empleados estatales, lo cual creó una falsa imagen de bienestar en 
el país; muy pronto vino la cuenta, el Perú fue declarado inelegible como acreedor ante organismos internacionales, se le negaron los créditos y empezó la terrible inflación; fue como si un jefe de familia no pague durante varios meses la luz, el teléfono, el agua y sus préstamos adquiridos y con ese dinero (aparentemente extra) empezara a comprar artefactos para la casa; podemos adivinar las consecuencias que esa actitud irresponsable acarrearía; eso ya sucedía en el Perú de 1987.

Casi al final de su gobierno y desesperado porque ya no había fondos en el tesoro público, intentó estatizar la banca, los seguros y las financieras; envió prepotentemente a gente de su entorno y con fuerte resguardo militar a "tomar" los Bancos y las financieras; el plan abortó por el decidido rechazo popular que salió a las calles a protestar en nutridas manifestaciones; el grito que se escuchaba era el siguiente: ¡Y va a caer... $\mathrm{Y}$ va a caer... caballo loco va a caer.......! (caballo loco era el alias de Alan García).

Durante su gobierno destrozó y desapareció dos monedas; primero el Sol que se devaluó tanto que tuvo que inventar el Inti (equivalente a mil soles) ya que era inmanejable pensar en soles, puesto que un helado costaba 1500 soles; pero eso no quedó allí, la inflación siguió y el Inti se empezó a devaluar también y tuvo que inventar otra moneda que se llamó Nuevo Sol (equivalente a mil intis); es decir que este nuevo sol era equivalente a un millón de los antiguos soles.

La terrible inflación empobreció y afectó más a la clase proletaria que a cualquier otra, se hizo común el trueque de mercancías ya que los billetes que se tenían en las mañanas perdían su valor adquisitivo hacia la tarde. Al recordar los $2700000 \%$ de inflación acumulada en sus cinco años de gobierno, hablamos de HIPERINFLACIÓN.

El jefe de Superintendencia de Banca, el aprista García Salvatecci, amigo de Carlos Manrique (el mayor estafador del siglo XX), protegió y pasó por alto su organización 
fraudulenta CLAE que más tarde fue intervenida empobreciendo y estafando a decenas de miles de peruanos que se quedaron sin sus ahorros de toda la vida.

No habían líneas telefónicas disponibles, si se pueden bajar las tarifas en buena hora, pero al menos ahora hay algo que bajar, en la época de Alan García simplemente no habían líneas nuevas y las existentes eran pésimas como todos los servicios del Estado; existía un mercado negro de líneas telefónicas por el que se pagaba (el que podía) hasta 5,000 dólares por línea.

Se creó el dólar MUC para las importaciones, es decir un dólar más barato que el dólar bancario al cual accedían los importadores previo trámite ministerial, el resultado fue obvio, algunos importadores del entorno presidencial como el actual reo Zanati accedían al dólar MUC inflando los montos necesarios, el excedente (dólar barato) iba a parar a los bolsillos de funcionarios corruptos.

Estos son algunos de los expedientes de García Pérez, en materia económica:

EXPEDIENTE N001-95

(Tren eléctrico, Canal 13 y dólares MUC)

En diciembre de 1995 la Fiscal Supremo Nelly Calderón en su dictamen 1750-95 concluye que “ ... se encuentran debidamente acreditadas la comisión de los delitos de Cohecho Pasivo y Enriquecimiento Ilícitos previsto y sancionado por los Arts. 349 ${ }^{\circ}$ y 361-A del Código Penal de 1924 en calidad de autor y como instigador en la comisión de los delitos de Colusión Ilegal y Negociación Incompatible, previsto y sancionado en los Arts. 344 y $345^{\circ}$ del Código Penal de 1924, respectivamente, así como la responsabilidad penal del procesado Alan Gabriel Ludwig García Pérez.”

En el Informe Final de la Instrucción abierta por Hugo Sivina Hurtado, Vocal Supremo Instructor, de marzo de 1996 contra Alan García Pérez, se concluye que "se encuentran acreditados los hechos delictivos imputados al procesado, opinando por su Responsabilidad Penal.....” 


\section{NELLY CALDERON}

Fiscal Supremo en lo Contencioso Administrativo

\section{HUGO SIVINA HURTADO}

Vocal Supremo Instructor

INFORME FINAL

Expediente $\mathrm{N}^{\circ} 001-95$

25.03 .96

“Señor Presidente :

“Que, el suscrito designado Vocal Supremo Instructor ... abro instrucción contra don Alan García Pérez, ex-Presidente Constitucional de la República del Perú, como instigador en la comisión de los delitos de Colusión Ilegal y Negociación Incompatible y, como autor de los delitos de Cohecho Pasivo y de Enriquecimiento Ilícito, en agravio del Estado Peruano, dictando en su contra mandato de Detención.”

\section{$2^{\circ}$ EN LO SOCIAL.}

- Lucha “antiterrorista”. El 7 de Agosto de 1985 Alan García ordena al ejercito peruano la “caza” de los subversivos. Ese día el teniente David Lama asesina a 7 inocentes Indígenas de la comunidad de Pucayacu con tiros en la nuca, sin motivos de acusación. El 14 de agosto de 1985, el subteniente Telmo Hurtado llega a Accomarca y asesina 69 campesinos, la mayoría mujeres y niños. Alan García fingió estar preocupado por este hecho y ordeno “una investigación”, pero el Senado con mayoría Aprista detuvo las investigaciones y los asesinos fueron puestos en libertad hasta el día de hoy.

- LA MATANZA EN LOS PENALES. El 17 de junio de 1986, Alan García se reunía con la Internacional Socialista, pretendiendo establecer un gobierno de izquierda pero en el fondo se estaba aliando a la derecha peruana. Entonces presos políticos de las cárceles de Chorrillos, Lurigancho y El Frontón se sublevan aprovechando la presencia de líderes mundiales reclamando por condiciones humanas para sus vidas, pues estaban siendo abusados de hambre y violencia física. 
Después de rendirse todos los presos, éstos fueron asesinados a quemarropa con tiros en la cabeza: 10 mujeres en Chorrillos, 172 hombres en Chorrillos y 154 hombres en El Frontón. Muchos de ellos eran presos comunes o reos acusados de terrorismo sin pruebas.

Alan García se desligo de las responsabilidades a pesar que el mismo ordenó al ministro del Interior Agustín Mantilla a "limpiar la zona” y dando un discurso en TV con su elocuente oratoria dijo "o se van ellos o me voy yo" refiriéndose a Mantilla.

Después de juicios, investigaciones y debates en un Senado dominado por el APRA sólo se sentenciaron a dos sub-oficiales de la Guardia Republicana. En 1990 cuando Fujimori ganó, una alianza APRA-Cambio 90 aprobó una ley que anuló la acusación constitucional contra Alan García.

Uno de los involucrados en estas matanzas es el actual vicepresidente de la República, el Almirante (r) Luis Giampietri Rojas.

- EL CASO CAYARA. El 14 de mayo de 1988 el Ejército llegó a Cayara, reunió a los pobladores en la plaza central, y ordenó a las mujeres y niños a presenciar el asesinato de 69 hombres indígenas echándolos al suelo y matándolos con bayonetas y machetes. Luego se obligó a los sobrevivientes a que entierren los muertos en una fosa común.

El senador aprista Carlos Enrique Melgar fue enviado a Cayara recién un mes después de esta masacre, pero se negó entrevistar a los testigos diciendo que el no era "ningún chulillo de testigos” y acusó a Amnesty International de “imbéciles y corruptos” por dañar la imagen de Perú en el mundo. La comisión Melgar felicita a los militares "por cumplir con su misión dentro del orden legal de la nación”.

En 1989 el caso es reabierto por la Fiscalía. En 1990 el Senado aprista cierra el caso y asciende y condecora al General Valdivia el responsable de esta matanza. 
- LA APARICIÓN DE LOS PARAMILITARES. Una de las herencias más nefastas de Alan García: el “Comando Rodrigo Franco”, grupo asesino formado por matones apristas con armas de la policía. Ellos asesinaron líderes sindicales, políticos de izquierda, abogados y testigos claves en los casos de las matanzas de indígenas por parte de los militares de Perú.

No fue casualidad que García “reorganizó” las fuerzas policiales y juntó la PIP, GR y GC en una Policía Nacional. Los puestos claves fueron repartidos entre Apristas.

También aparecieron otros grupos paramilitares: "Comando Chavin”, “Comando Manuel Santana”, “Comando Haya Vive”, “Comando Manuel Cipriano”, “Águilas Peruanas”. “Pelotón Punitivo Peruano”, etc. sumando mas de 11,000 asesinatos de inocentes peruanos.

El ministro de Interior Agustín Mantilla presentó varios informes distrayendo la atención del público hacia denuncias contra políticos de izquierda, eventualmente se descubrió que Mantilla -quien desapareció misteriosamente después del exilio de Alan- era parte del “Comando Rodrigo Franco” grupo que formó en la DIRCOTE (Dirección Contra el Terrorismo) de la Policía Nacional.

\section{LOS ESTUDIANTES}

Docenas de estudiantes de las Universidades Católica, UNI, San Marcos, Villarreal fueron desaparecidos y luego encontrados muertos en acequias, chacras, playas. Estas matanzas fueron obra de los grupos paramilitares.

\section{LOS CAMIONES DE LOS MOLINOS}

Un escuadrón del MRTA se enfrentó al ejército ocultándose en dos camiones llenos de inocentes civiles en Junín, el 28 de abril de 1989 el ejército mató mas de 62 personas, la mayoría ancianos y niños que no tenían que ver con la guerra, ellos no fueron capturados sino matados a quemarropa. Alan García visitó el lugar y caminó encima de los cuerpos tirados en el suelo, felicitando a los responsables Ministro de Defensa Enrique López Albújar y el jefe del Comando Conjunto, Artemio Palomino Vargas. 


\section{EL LEGADO DE GARCÍA PÉREZ}

Perú se convirtió en sinónimo de matanza, muerte, impunidad. La violencia empeoraba cada día. La lucha antisubversiva fue la excusa para que grupos paramilitares vinculados al Partido Aprista asesinaran gente inocente. La corrupción invadió el Poder Judicial y Legislativo, absolviendo a los culpables y encarcelando a sub-oficiales sin influencias y que eran indígenas en su mayoría. El resultado fue que Sendero Luminoso y el MRTA aumentaron sus fuerzas y rodearan Lima.

El permanente abuso y la violación de derechos humanos es el legado mas triste del gobierno de García, la crisis económica y la corrupción generalizada abrieron el camino a un candidato desconocido llamado Alberto Fujimori, quien permitió que García escapara del país a su asilo de lujo en Colombia y Francia.

La población peruana nunca más debe pensar que el hoy Presidente de la República, cometió errores. Eso es rotundamente FALSO. Fiel a los principios del APRA, quien encabezó el período '85-'90, los actos de gobierno de García Pérez estuvieron muy bien encaminados a los objetivos predeterminados: el enriquecimiento ilícito (hoy Camposol es una pequeña muestra de esta afirmación, así como lo son las lujosas propiedades adquiridas por García Pérez en las playas del sur limeño, de Chacarilla o el impresionante condominio ii en París $i$ !), así como el desarrollo de actividades fascistas, arriba reseñadas, que estuvieron dirigidas, obviamente a desarticular sindicatos y partidos de izquierda con el auxilio de sus hordas fascios como el Comando Rodrigo Franco. Decir que Alan García cometió errores es, entonces, FALTAR A LA VERDAD. iii No fueron errores, fueron DELITOS !!!

Sin embargo, Alan García nunca quiso ser juzgado por los tribunales peruanos. Es por ello que alegó prescripción de los delitos por los cuales fue condenado en condición de reo contumaz. Es decir, sostuvo que ya pasó el tiempo para juzgar sus delitos (recuérdese la entrevista que Mónica Delta, entonces periodista de Panamericana TV, le hiciera en Colombia hacia enero del 2001). La razón es muy simple: si García Pérez fuera juzgado en 
forma objetiva y real, de seguro sería sentenciado, porque las evidencias son abrumadoras. Los expedientes judiciales así lo demuestran.

La acusación de una fiscal suprema proba e intachable, como Nelly Calderón, ex Fiscal de la Nación, es contundente. El dictamen del juez que estudió el caso, el Vocal Supremo Hugo Sivina, magistrado igualmente honesto, acusa también a García Pérez. Por eso él rehuyó la justicia con todas las argucias y leguleyadas a su alcance, pero sobretodo gracias a la labor nefasta de impunidad que realizaron sus congresistas, así como la complicidad de la cabeza de la mafia corrupta fujimontesinista.

Recordemos lo que sucedió durante el inicio del gobierno fujimorista. Los parlamentarios de cambio 90, siguiendo órdenes de su líder, se unieron a los apristas en las votaciones decisivas para NO lograr denunciar constitucionalmente al entonces ex presidente García. Gracias a Fujimori, García consiguió librarse de un juicio justo y necesario.

Sucedió una vez ¿Qué sucederá ahora? ¿Favor con favor se paga? ¿Qué nos garantiza que no sean ahora los parlamentarios apristas quienes se agrupen junto a los escuderos de Fujimori para que los crímenes del fujimontesinismo queden impunes?. Nada. Ya lo estamos viendo en este Congrezoo. La segunda semana de marzo del 2008, apristas y miembros del fujimorato se unieron para blindar a Tula Benítes, personaje trujillano miembro de la familia del ex presidente de la Corte Suprema, Walter Vásquez Vejarano, protector de la Benítes y del esposo de ésta: el fiscal Fermín Caro, primo hermano de un despreciable tránsfuga en el actual Congreso, Carlos Torres Caro,"el fotógrafo”.Lo único que nos garantiza este nuevo gobierno de Alan García es que la justicia termine totalmente enterrada bajo el polvo de la corrupción. Pero lo que estamos viendo en economía hace renacer temores de la espiral inflacionaria que los peruanos vivimos en su primera gestión.

Recuérdese además que los jueces nombrados durante el régimen aprista e inclusive los nombrados por el régimen fujimontesinista, TODOS son de tendencia aprista o filoaprista, el Consejo Nacional de la Magistratura es lo mismo (Teófilo Idrogo, Vàsquez Vejarano o Rodríguez Medrano, y todos los etcéteras......¿¿acaso no tienen militancia?). 
En fin, a pesar del desgobierno entre 1985-90, la población electoral peruana, así como volvió a elegir a Castilla, o a Piérola, o a Leguía, o a Belaúnde, así también lo hizo con García Pérez y, hoy estamos atestiguando una nueva espiral inflacionaria -aun cuando menor que hacen veinte años-, así como actos de inmoralidad y corrupción a extremos tales que nos hacen reflexionar y preguntarnos $i$ por qué siempre tenemos un comportamiento similar de la población peruana frente a personajes que demostraron, con sus actos, que nunca sintieron la moral ni al Perú como algo suyo?.

\section{EPÍLOGO}

Hoy, en pleno juicio al extraditado ex dictador Alberto Fujimori, personaje japonés que gobernó Perú durante los diez años que hoy todos reconocemos como uno de los períodos más corruptos de la historia nacional, habiendo ya sido sentenciado en uno de los juicios que afronta (falsedad genérica, abuso de autoridad asociación ilícita para delinquir, en los seguidos por el allanamiento de la vivienda de doña Trinidad Becerra, esposa de su ex asesor Vladimiro Montesinos, en su desesperado intento de desaparecer todo video y/o audio que lo incrimine), y en pleno juicio oral por delitos de lesa humanidad, en su probada participación como autor intelectual de matanzas como las de Barrios Altos y de La Cantuta, y mientras los más distinguidos juristas y analistas dan por hecho una sentencia de 35 años, el otoñal dictador prepara “su” campaña electoral con miras a las elecciones del 2011, riéndose de la posibilidad de ser condenado a nunca salir vivo de la prisión a la que está confinado. Claro, conoce bien la historia de un país que pronto olvida, a pesar de sus padecimientos. 


\section{BIBLIOGRAFÍA.}

- Archivos periodísticos de :

- Caretas

- El Comercio

- El Correo

- El Expreso

- La República

1. BASADRE, Jorge

1983 Historia de la República del Perú. Ts. III, IV V. Edit. Universitaria, Lima.

2. BONILLA, Heraclio

1980

La Era del Guano. En Nueva Historia General del Perú.

Ediciones Mosca Azul. Lima

3. CEDEÑO LEÓN, José

2005

Historia del Perú. Manual. Ediciones Integral. Trujillo.

4. DURAND F. Luis

1993 República:1900-1993; en Compendio Histórico. Ed. Milla Batres

5. GUERRA MARTINIERI, Margarita

1993 Historia general del Perú. T VII. Edit. BRASA. Lima

6. MANRIQUE, Nelson

$1998 \quad$ Historia de la república; Amauta Editores. Lima

7. ROEL PINEDA, Virgilio

1991 Historia social y económica del mundo moderno. Lima

8. YÉPEZ DEL CASTILLO, Ernesto

1980 Expansión mercantil capitalista. En Historia del Perú, procesos e instituciones. Edit. Mejía Baca. Lima. 